\title{
Health and Healthcare as Infinite Games
}

\section{Neil E Grunberg'* and Erin S Barry ${ }^{2}$}

${ }^{1}$ Professor, Department of Military and Emergency Medicine, Uniformed Services

University of the Health Sciences, Bethesda, MD, USA

${ }^{2}$ Assistant Professor, Department of Military and Emergency Medicine, Uniformed

Services University of the Health Sciences, Bethesda, MD, USA

*Corresponding Author: Neil E Grunberg, Professor, Department of Military

and Emergency Medicine, Uniformed Services University of the Health Sciences,

Bethesda, MD, USA.

DOI: $10.31080 /$ ASMS.2022.06.1201
Received: January 04, 2022

Published: February 18, 2022

C) All rights are reserved by Neil E Grunberg and Erin S Barry.

\begin{abstract}
"Life is a game" and health and healthcare should be seen as infinite, not finite, games. To succeed at infinite games requires an understanding of what is meant by infinite games as well as the willingness to embrace this mindset. Infinite games are continuous without a designated beginning or ending and do not have referees or judges, specified outcomes, or observers in the same way as finite games. Individuals and organizations that have an infinite game mindset are stronger and benefit because they are always learning and growing with no designated end at which point one stops trying, contributing, or participating. Five essential practices to embrace and operate with an infinite mindset are described as they relate to health and healthcare: (1) Advance a just cause; (2) Build trusting teams; (3) Study their worthy rivals; (4) Prepare for existential flexibility; and (5) Demonstrate the courage to lead. If health is perceived as an infinite game, then health-enhancing, injury-avoiding, and disease-preventing behaviors are more likely to be regular and consistent aspects of daily life. Similarly, if healthcare is perceived as an infinite game, then patients and practitioners will more likely focus on health-promotion best practices, injury and illness prevention, education about and encouragement to engage in behaviors and cognitions related to wellness.
\end{abstract}

Keywords: Just Cause; Trusting Teams; Worthy Rivals; Existential Flexibility; Courage to Lead

\section{Introduction}

"Life is just like a game. First you have to learn rules of the game, and then play it better than anyone else".

\section{-- Albert Einstein}

"So does treating life like a game necessarily empty it of meaning and moral value? It depends what game you're playing."

-- Jules Evans

It has often been said that "life is a game." This phrase can be misinterpreted as a way of trivializing the seriousness of existence, or can be interpreted as a mantra to help cope with the challenges and difficulties of life. Regardless of one's reason for characterizing life as a game, there is value in considering what type of game it might be because the type of game determines how best to approach or to play it successfully.

James Carse [1] distinguished between finite and infinite games. According to Carse, finite games have specific rules, boundaries, winners, and losers. Finite games are played to win and clearly begin and end. These games have rules and regulations, timeframes, identifiable players and eligibility to participate, referees or judges, specified outcomes, and non-participant observers. In contrast, infinite games are continuous without a designated beginning or 
ending. Infinite games do not have referees or judges, specified outcomes, or observers in the same way as finite games. Recently, Simon Sinek [2] applied Carse's distinction to businesses and asserted that an infinite game and mindset perspective results in stronger organizations and benefits because those who have this perspective are always learning and growing. Business activities are continuous and there is no designated end at which point one stops trying, contributing, or participating.

We submit that health and healthcare also should be approached as infinite games to optimize wellness. When health and healthcare are perceived and dealt with as infinite games - i.e., to continuously address, value, and embrace best health practices; to focus on health promotion and injury and illness prevention; to consider all aspects of health - wellness is more likely to be optimized.

If health is perceived and dealt with as a finite game, then behaviors relevant to positive physical and mental health (e.g., personal hygiene, proper nutrition, exercise, stretching, sleep hygiene, dental care, moderate drinking, stress management, positive attitudes, social interactions) may only be followed for limited periods of time while an acute health challenge, injury, or illness is apparent and being addressed. In contrast, if health is perceived as an infinite game, then health-enhancing, injury-avoiding, and diseasepreventing behaviors (including vaccinations, eating healthy, exercising, etc.) are more likely to be regular and consistent practices. When individuals adopt an infinite mindset regarding health, they are more likely to focus on their own health in a more involved, ongoing, and unending manner.

Similarly, if healthcare is perceived and dealt with as a finite game by healthcare professionals and patients, then the focus is likely to be on treatment of a particular injury or illness to attenuate or to resolve that particular health problem as an end point; providing health-promoting and disease-preventing activities or advice may be disregarded. In contrast, if healthcare is perceived as an infinite game, then practitioners will more likely focus on healthpromotion best practices, injury and illness prevention, education about and encouragement to engage in behaviors and cognitions related to physical and psychological wellness for themselves as role models and for their patients. When healthcare practitioners adopt an infinite mindset, they are more likely to focus on their patients' health in a more involved, ongoing, and unending manner. As a result, patients are more likely to expect receiving guidance from healthcare professionals on how to best enhance health following each interaction, whether to treat a health problem or as a wellness visit.

\section{Essential practices of leaders for an infinite mindset}

Sinek [2] identified five essential practices of leaders who embrace and operate with an infinite mindset: (1) Advance a just cause; (2) Build trusting teams; (3) Study worthy rivals; (4) Prepare for existential flexibility; and (5) Demonstrate the courage to lead. Each of these practices can be applied to optimize health and healthcare.

Advancing a Just Cause gives an individual, team, and organization meaning. It focuses on our raison d'etre, vision, or aspirations, and it inspires and motivates us to engage in our infinite game. A Just Cause must be: for something (affirmative, optimistic, and mission-focused); inclusive (open for all to contribute in a psychologically safe context with mutual respect); service oriented (for the benefit of others, focusing on patients/customers and team members); resilient (able to adapt to various situations and endure change); and idealistic (big, bold, and visionary) [2]. Achieving and maintaining health in ourselves and others is a Just Cause and is, therefore, relevant to patients and to the work of healthcare providers. Advancing a Just Cause also serves to support, encourage, and energize teams and organizations when dealing with endless, infinite healthcare issues and challenges.

Focusing on health as advancing a just cause is likely to encourage behaviors and practices that optimize health and prevent the likelihood of injury or illness. This perspective is likely to help prioritize taking time to exercise, to prepare and eat healthy meals, to sleep, to appreciate each day, and to engage in personal and social activities that enhance well-being. Viewing healthcare as a just cause is likely to encourage patients and healthcare professionals to see and engage meaningfully with each other. This approach also is likely to help individuals reflect upon their contributions and, perhaps, avoid burnout.

Building Trusting Teams is essential to health and healthcare. Healthcare teams include providers from different fields (physicians, nurses, dentists, psychologists, physical therapists, occupational therapists, social workers, and so on), patients, and patients' significant others. Building trust requires awareness of what trust is and how to optimize it. Burchard, Grunberg, and Barry [3] of- 
fer a model of trust consisting of: authenticity, safety, consistency, dependability, ownership, and competence. This model guides all members of the team (to include providers and patients) to determine where trust exists and where trust can be improved to build trusting teams that maximize performance.

Healthcare requires teams that perform and communicate competently, are cohesive, and have high morale [4]. Healthcare teams are often transient as health status of patients changes. If healthcare teams hold an infinite mindset, then hand-offs within shifts, transferring patients to other professionals' care, and follow-up with patients after a visit or procedure for a particular injury, illness, or regular health check-up would be viewed as continuous care as the long, endless view is embraced. An infinite mindset among members of healthcare teams emphasizes:

- $\quad$ Focusing on mission and team. When the goal is understood by all, responsibility is shared to achieve the mission and to work together as a cohesive team [5].

- Including team members with relevant and diverse perspectives, knowledge, skills. Healthcare teams are complex, as Fiscella and McDaniel [6] explain. Diverse teams achieve goals with multiple perspectives, knowledge, and skills.

- Being adaptive in a supportive environment. Healthcare teams work in physically and emotionally challenging environments [7]. Team members need to be aware of the context in which they are working $[5,8]$. For effective team work, emotionally safe environments, or psychological safety, are necessary $[5,9,10]$.

- Understanding roles and responsibilities of each team member. It is important to know each team member's roles and responsibilities to build an effective team [5,8]. Knowledge, skills, and attributes each individual brings to the team should be understood to determine who is able to accomplish which tasks. Most importantly, every member of the team must be valued and display mutual respect towards each other and as part of the team [8].

- Clear and effective communication across all levels and among team members. Communication includes sending and receiving information, verbally or non-verbally. Effective team members need to use clear, continuous communication for teams to be successful [8], with closed-loop communication being especially useful within healthcare teams [6].
- Embracing shared leadership. As Weiss, Tilin, and Morgan noted, "Leadership in the interprofessional healthcare team means that both the designated leader and members must be willing to share the responsibilities of team leadership and be cognizant of group dynamics in order to work with widely diverse skills, values, and interests [11]". Shared leadership is "an emergent team property that results from the distribution of leadership influence across multiple team members" [12] and focuses on "emergent, informal, and dynamic 'leadership' brought about by the members of the collective itself [13]". Team success is dependent on collective perspectives, knowledge, and skills of all team members [14-17].

When trusting teams are built among health care professionals, patients, and patients' significant others, these teams can share mission and provide support to encourage and reinforce each member's commitment to an infinite mindset regarding health and healthcare.

Studying worthy rivals includes behaviors, cognitions, and motivations that "rival" (or challenge) health as well as infectious diseases and congenital health-related conditions. These behaviors include exercise, eating, sleep, and drug use. Individuals who exercise regularly are less depressed, angry, and stressed; more trusting; and perceive their health to be better compared to people who do not exercise regularly $[18,19]$. Exercise includes aerobics, weight training, Tai Chi, yoga, and group activities that reduce stress and anxiety, improve mood, increase self-esteem, and reduce social isolation [20-23].

Proper nutrition is linked to positive well-being [24,25] and less depressive symptoms. Comfort foods can enhance well-being acutely [26]. Food deprivation generally decreases well-being [27]. Hunger also can increase aggressive and impulsive behaviors.

Quality of sleep affects performance and well-being [28]. Most healthy adults need seven to nine hours of sleep each night [29]. Lack of sleep and poor sleep hygiene negatively affects well-being and can compromise optimistic outlook and social functioning [30].

Licit (e.g., alcohol, nicotine, caffeine) and illicit (e.g., illegal use of Rx, non-Rx, and performance enhancing) drug use can affect well-being. Some licit drugs are used to enhance well-being and to 
attenuate stress [31]. However, there are health risks of continuous drug use [31,32]. Some illicit drugs are used to enhance well-being acutely, but long-term effects usually lead to physical, psychological, social, and legal problems [32].

Cognitions include awareness, optimism, resilience, beliefs, and biases. Awareness entails a perception of one's environment. Manipulation of awareness (e.g., mindfulness) can decrease stress and increase performance [33-35]. Beliefs and biases affect perceptions and actions regarding immunizations, benefits and risks of particular procedures and medications, and decisions whether or not to follow medically-recommended prevention and treatment regimens.

Optimism is the extent to which favorable expectancies are held about the future and is related to well-being [36,37]. Generating mental imagery of positive future events, instead of focusing on negative thoughts or "thinking traps" (catastrophizing, focus on negative), results in better well-being [38].

Psychological resilience is "the process of adapting well in the face of adversity, trauma, tragedy, threats, or significant sources of stress [39]". Resilience factors contribute to a decrease in negative reactions to stressors [40]. Thriving - to grow and develop subsequent to stress such that the individual becomes stronger - maximizes well-being.

Racism and sexism are negatively correlated with psychological, social, and/or physical well-being [41]. Being the subject of or expressing other biases/prejudices also diminishes well-being.

Motivations explain why people behave as they do. Emotions, or experiences of affect, are expressions of motivation. Positive emotions enhance and reflect well-being, whereas negative emotions are inversely related to well-being.

Arousal (or stress) is related to performance and psychological state following the Yerkes-Dodson inverted U-shaped function [42]. As one's arousal or stress level increases, so does performance and hedonic (or emotional) state. When stress is high and exceeds one's coping ability, performance and hedonic state decrease. The point at which the effects of stress go from positive to negative differs among individuals, depending on genetics, prenatal environment, childhood stress, personality, resilience, and other factors. Medical professionals experience job stress and burnout that negatively affect well-being. Individuals who lack social support from supervisors and co-workers display worse well-being and more unfavorable work outcomes [43].

Healthcare providers and patients must work to reduce and combat "rivals" to health such as unhealthy behaviors (e.g., cigarette smoking, lack of exercise, inadequate sleep, poor nutrition, excessive alcohol consumption), lack of compliance with medically-recommended regimens, risky behaviors with high probably of injury or illness, and stress. Healthcare providers who apply and encourage an infinite game mindset highlight these issues to patients, colleagues, and healthcare team members. Healthcare providers and patients who understand the "worthy rivals" that threaten health will remember that these threats are close by and that behaviors, cognitions, and motivations consistent with health as an infinite game are effective adversaries for these "rivals" to health.

Preparing for existential flexibility can be central to psychological health of patients and of healthcare professionals. Facing serious health challenges with current knowledge of best practices, understanding of potential and likely outcomes, and preparation for worst case scenarios (including permanent physical or psychological incapacitation or death) can help patients, patients' significant others, and practitioners make informed decisions together. Although it is certainly difficult to face the end of life and seriously debilitating illnesses and injuries, there is substantial value to prepare for these possibilities by addressing psychological, social, financial, and spiritual needs. Oncologists who prepare cancer patients and their significant others with truthful diagnoses that include likely time courses of disease progression often are greatly appreciated because patients and their significant others can decide whether to engage in desired behaviors before it is too late and can prepare as best they can for the end. Physical and occupational therapists who work with patients recovering from serious injuries (including limb loss and traumatic brain injuries) must help patients learn how to cope with physical, psychological, and social limitations that may be long-lasting about substance abuse counselors must work hard to establish rapport, trust, and effective communication with patients who face the challenge of abstaining from and living without addictive drugs.

As difficult as it is for patients sometimes to hear the truth about their health, prognosis, and conditions, it also is hard on healthcare 
providers who must deliver that news. Preparing for and addressing these difficult health issues is a key element to adopt an infinite mindset in healthcare. Existential questions are real and must be faced in healthcare. An infinite mindset by patients and by practitioners can be valuable to help make difficult decisions and to appreciate each healthy day.

Demonstrating the courage to lead is an important element of adopting an infinite mindset to health and healthcare. According to Sinek, "Courageous leaders are strong because they know they don't have all the answers and they don't have total control. They do, however, have each other and a "just cause" to guide them... When leaders exercise the "courage to lead," the people who work inside their organizations will start to reflect that same courage [2]".

Healthcare providers are leaders within their professions and specialties and are leaders for the patients for whom they care. As leaders within their professions and specialties, healthcare providers help set goals, support, inspire and encourage their colleagues in the important work of healthcare. As leaders for their patients, healthcare providers similarly help set goals, support, inspire and encourage patients and also apply knowledge and skills for the well-being of patients. Adopting an infinite mindset is likely to help healthcare providers to have the courage to lead as health is viewed as a never-ending process that is the essence of life.

Individuals who are willing to take responsibility for their own health become their own healthcare leaders as well. Embracing the responsibility to make meaningful decisions for ourselves and, where appropriate, for others (including patients, children, significant others, parents, friends) is an important aspect of the infinite mindset and approach to health and healthcare. When we view health as an infinite game, then behaviors, cognitions, and motivations that contribute to health are never-ending and every day of health is precious.

\section{Conclusion}

If life is perceived as an infinite game, then health and healthcare can be seen as continuous without a designated beginning or ending, without referees or judges, specified outcomes, or observers in the same way as finite games. Individuals with an infinite game mindset benefit themselves, their teams, and their organization as they are constantly learning and growing with no designated end point. The five essential practices of leaders who embrace and operate with an infinite mindset described how this mindset relates to health and healthcare. By following these practices (advance a just cause; build trusting teams; study worthy rivals; prepare for existential flexibility; and demonstrate the courage to lead), health and healthcare can become more effective through health-enhancing, injury-avoiding, and disease-preventing behaviors that should become part of our daily life. Additionally, when healthcare is perceived as an infinite game, practitioners can focus on health-promotion, injury and illness prevention, education about and encouragement to engage in behaviors and cognitions related to wellness for themselves as role models and for their patients.

\section{Acknowledgments}

N/A.

\section{Disclosure}

The author reports no conflicts of interest in this work. The opinions and assertions contained herein are the sole ones of the authors and are not to be construed as reflecting the views of the Uniformed Services University, The Henry M Jackson Foundation for the Advancement of Military Medicine, or the Department of Defense.

\section{Competing Interest Statement}

The authors do not have any conflicts of interest.

\section{Funding}

None declared.

\section{Consent Statement/Ethical Approval}

Not required.

Bibliography

1. Carse JP. "Infinite and finite games. A Vision of Life as Play and Possibility". New York: A division of Macmillan (1986).

2. Sinek S. "The infinite game". Penguin (2019).

3. Burchard MA., et al. "Toward Understanding and Building Trust for Practicing and Emerging Healthcare Professionals: The ASC-DOC Trust Model". MedEdPublish (2020): 9. 
4. Barry ES and NE Grunberg. Healthcare teams, in Cultivating Leadership in Medicine, J.F. Quinn and B.A. White, Editors. Kendall Hunt Publishing Company: Dubuque, IA (2019): 117130.

5. Barry ES., et al. "Leadership and followership in military interprofessional healthcare teams". Military Medicine 186.S3 (2021): 7-15.

6. Fiscella K and SH McDaniel. "The complexity, diversity, and science of primary care teams". American Psychologist 73.4 (2018): 451.

7. Ervin JN., et al. "Teamwork in the intensive care unit". American Psychologist 73.4 (2018): 468.

8. Varpio L., et al. "Interprofessional Healthcare Teams in the Military: A Scoping Literature Review". Military Medicine 183.11/12 (2018): e448-454.

9. O’Donovan R and E McAuliffe. "Exploring psychological safety in healthcare teams to inform the development of interventions: combining observational, survey and interview data". BMC Health Services Research 20.1 (2020): 1-16.

10. Edmondson AC., et al. "Understanding psychological safety in health care and education organizations: A comparative perspective". Research in Human Development 13.1 (2016): 65-83.

11. Weiss DF., et al. "The interprofessional health care team: Leadership and development". 2014: Jones and Bartlett Publishers.

12. Carson JB., et al. "Shared leadership in teams: An investigation of antecedent conditions and performance". Academy of Management Journal 50.5 (2007): 1217-1234.

13. Contractor NS., et al. "The topology of collective leadership". The Leadership Quarterly 23.6 (2012): 994-1011.

14. Day DV., et al. "Leadership capacity in teams". The Leadership Quarterly 15.6 (2004): 857-880.

15. Friedrich TL., et al. "Collective leadership behaviors: Evaluating the leader, team network, and problem situation characteristics that influence their use". The Leadership Quarterly 27.2 (2012): 312-333.

16. Serban A and AJ Roberts. "Exploring antecedents and outcomes of shared leadership in a creative context: A mixedmethods approach". The Leadership Quarterly 27.2 (2016): 181-199.
17. Zhu J., et al. "Shared leadership: A state-of-the-art review and future research agenda". Journal of Organizational Behavior 39.7 (2018): 834-852.

18. Hassmen P., et al. "Physical exercise and psychological wellbeing: a population study in Finland". Preventive Medicine 30.1 (2000): 17-25.

19. Stubbe JH., et al. "The association between exercise participation and well-being: a co-twin study". Preventive Medicine 44.2 (2007): 148-152.

20. Wang C., et al. "Tai Chi on psychological well-being: systematic review and meta-analysis". BMC Complement Alternate Medicine 10 (2010): 23.

21. West J., et al. "Effects of Hatha yoga and African dance on perceived stress, affect, and salivary cortisol". Annals of Behavioral Medicine 28.2 (2004): 114-118.

22. Trainor S., et al. "Leisure activities and adolescent psychological well-being”. Journal of Adolescence 33.1 (2010): 173-186.

23. Brown B., et al. "Happiness through leisure: the impact of type of leisure activity, age, gender and leisure satisfaction on psychological well-being". Journal of Applied Recreation Research 16.4 (1991): 368-392.

24. Jacka FN., et al. "Association of Western and traditional diets with depression and anxiety in women". American Journal of Psychiatry 167.3 (2010): 305-311.

25. Blanchflower DG., et al. "Is psychological well-being linked to the consumption of fruit and vegetables?" Social Indicators Research 114.3 (2013): 785-801.

26. Linley PA., et al. "Two simple, brief, naturalistic activities and their impact on positive affect: feeling grateful and eating ice cream". Psychology of Well-Being: Theory, Research and Practice 3.1 (2013): 1-14.

27. Carter KN., et al. "The association of food security with psychological distress in New Zealand and any gender differences". Social Science and Medicine 72.9 (2011): 1463-1471.

28. Steptoe A., et al. "Positive affect, psychological well-being, and good sleep". Journal of Psychosomatic Research 64.4 (2008): 409-415.

29. National Sleep Foundation. 25 Random Facts about Sleep. (2015). 
30. Haack M and JM Mullington. "Sustained sleep restriction reduces emotional and physical well-being". Pain 119.1-3 (2005): 56-64.

31. Grunberg NE., et al. "Stress and drug use. The handbook of stress science". Biology, Psychology and Health (2011): 287300 .

32. National Institute on Drug Abuse. "The science of addiction: Drugs, brains, and behavior" (2010).

33. Sonnentag S. "Psychological Detachment From Work During Leisure Time The Benefits of Mentally Disengaging From Work". Current Directions in Psychological Science 21.2 (2012): 114-118.

34. Johnson DC., et al. "Modifying resilience mechanisms in at-risk individuals: a controlled study of mindfulness training in Marines preparing for deployment". American Journal of Psychiatry 171.8 (2014): 844-853.

35. Jha AP., et al. "Minds "at attention": mindfulness training curbs attentional lapses in military cohorts". PLoS One 10.2 (2015): e0116889.

36. Carver CS., et al. "Optimism". Clinical Psychology Review 30.7 (2010): 879-889.

37. Augusto-Landa JM., et al. "Does perceived emotional intelligence and optimism/pessimism predict psychological wellbeing?" Journal of Happiness Studies 12.3 (2011): 463-474.

38. Blackwell SE., et al. "Optimism and mental imagery: a possible cognitive marker to promote well-being?" Psychiatry Research 206.1 (2013): 56-61.

39. American Psychological Association. "Building your resilience" (2012).

40. Adler AB., et al. "Deployment psychology: Evidence-based strategies to promote mental health in the military". 2011: American Psychological Association (2011).

41. Kaniasty K. "Predicting social psychological well-being following trauma: The role of postdisaster social support". Psychological Trauma: Theory, Research, Practice, and Policy 4.1 (2012): 22.

42. Yerkes RM and JD Dodson. "The relation of strength of stimuls to rapidity of habit-formation". Journal of Comparative Neurology and Psychology (1908): 459-482.
43. Burke RJ., et al. "Job demands, social support, work satisfaction and psychological well-being among nurses in Spain". ESADE Business School Research Paper 233 (2012).

\section{Assets from publication with us}

- Prompt Acknowledgement after receiving the article

- Thorough Double blinded peer review

- Rapid Publication

- Issue of Publication Certificate

- High visibility of your Published work

Website: www.actascientific.com/

Submit Article: www.actascientific.com/submission.php

Email us: editor@actascientific.com

Contact us: +919182824667 